\title{
NUTRITIONAL STATUS OF PRIMARY SCHOOL CHILDREN WITH MID-DAY MEAL PROGRAM
}

\author{
Md Mushfiqur Rahman*, Mortahina Rashid, Lee Shanta Mondol, Md Arifuzzaman \\ Khan, Laila Nur, Munmun Hossain and Rafia Hossain \\ National Institute of Preventive and Social Medicine, Bangladesh
}

\begin{abstract}
This study was conducted to determine the nutritional status of primary school children with the mid-day meal program. A cross-sectional study was conducted in 05 primary schools with the mid-day meal program of Sundarganj Upazila of Gaibandha district from January 01 to December 31, 2017. A total of 357 primary school children of class IV and class V were selected using a systematic sampling technique. A semi-structured questionnaire was used to collect data from the school children of mid-day meal program schools. The anthropometric measurements such as weight, height and MUAC were measured for each child individually. Then weight and height were used to calculate the $\mathrm{Z}$ score to interpret nutritional status. The mean age of children was $10.83 \pm 1.03$ years. The mean weight and mean height of children were $32.40 \pm 7.21 \mathrm{~kg}$ and $141.22 \pm 8.52 \mathrm{~cm}$ respectively, and the mean MUAC was $19.65 \pm 2.31 \mathrm{~cm}$. It was revealed that $91.3 \%$ of children were normal by Height for Age (HAZ) and $89.1 \%$ were normal by Weight for Age (WAZ), and the remaining children were stunted and underweight respectively. $78.8 \%$ of children used anthelminthic drugs regularly and among them, $74.3 \%$ were normal in Weight for Age $\mathrm{Z}$ score. Socioeconomic status, dietary habit, physical activity and anthelminthic use by the child were found to be determinants of their nutritional status.
\end{abstract}

Keywords: Mid-day meal, Primary school children, Nutrition, Anthropometric, Stunted, Underweight, School Health

\section{Introduction}

Primary school age is a dynamic period of the child's physical, mental and social development (Hasan I, 2011). Today's children are the citizens of tomorrow's world; their survival, protection, and development are the prerequisite for humanity's future development (Chabra P, 1996). Children are the most vulnerable part of the population who are mostly suffering from malnutrition, that is, undernutrition as well as over-nutrition. Undernutrition occurs due to the deficiency of different types of nutrients. Deficiency of nutrients during the childhood period causes irreversible and serious consequences in later life. Childhood undernutrition, even in the short term can cause negative effects on the cognitive, mental and social development that leads to poor performance in the school.

Today the invisible malnutrition touches the lives of approximately one-quarter of the developing world's young children. It quietly steals their energy, gently restrains their growth, and gradually lowers their body resistance. Malnutrition is closely related to various types of infection and illness. It is a vicious cycle. About half of all severe child malnutrition cases are precipitated not primarily by the lack of food but by intestinal parasites, fever and infection, especially diarrheal infection that depresses the appetite, burns the energy and lowers the bodyweight of the child. The net result is that more than thousands of young children die every day from malnutrition and infection.

Thatcher, Amirthaveni and Barikor suggested that the children's health is dependent upon food intake that provides sufficient energy and nutrients to promote optimal physical, social, cognitive growth and development. Inadequate energy and nutrients have poor outcomes, including growth retardation, iron deficiency anemia, poor academic performance, and psychosocial difficulties (Handa R, 2008). Waterlow reported that the aetiology of 
linear growth retardation is multifactorial but has been explained by three significant factors: poor nutrition, high levels of infection and problematic mother-infant interaction, which is closely related to the socioeconomic status of the family (JC, 1994).

Malnutrition affects children's well-being and ability to learn and play normally; therefore, healthy food choices may improve a child's well-being and ability to learn and normally play (R, 2007). Furthermore, research has shown that dietary habits in childhood impact growth, development, and disease prevalence throughout the life cycle. Healthy eating habits should thus be established during childhood (ADA, 2010). The quality of children's diets usually declines as they move from childhood to adolescence. Eating healthily is usually not a priority for adolescents, and poor eating patterns may thus add a risk for current and future health problems (Story M, 2002). Many school-based nutrition programs have been implemented globally, focusing mainly on obesity, the importance of activity of vegetables and fruit in the diet (ADA, 2010).

The school-age period is nutritionally significant because this is the prime time to build up body stores of nutrients for adolescents' rapid growth. In children, a protein energy-deficient diet results in underweight, wasting, lowered resistance to infection, stunted growth, and impaired cognitive development and learning (Handa R, 2008). Mid-day meal program in school aims to improve the nutritional status of the school children. It provides supplementary food to the school children, not a substitute for the home diet. The mid-day meal should supply One-third of the total energy requirement of the child.

Anthropometry is the most useful tool for assessing the nutritional status of children for practical purposes. Many anthropometric indicators are in use, such as mid-upper arm circumference, weight for age, height for age, weight for height, and body mass index. Most of these indicators need to be used along with specific reference tables, for example, the National Center for Health Statistics (NCHS) tables for interpreting data.

The present study has been designed to determine the nutritional status of primary school children with a midday program and determine the primary school children's sociodemographic characteristics.

\section{Objectives}

1. To determine the nutritional status of the primary school children with the mid-day meal

2. To determine the sociodemographic status of the respondents

\section{Materials and Methods}

This cross-sectional descriptive study was conducted from January 01 to December 31, 2017, at 05 Government Primary Schools of Sundarganj Upazila of Gaibandha District, Bangladesh, selected purposively. The study population was the students of Class IV and Class V, who was willing to participate in the study. A total of 357 students were included in this study by systematic sampling. A pre-tested semi-structured questionnaire was used to collect data through face to face to interviews. Before taking the interview, verbal consent from Headmaster and informed written consent was taken from the participants. Collected data were edited, processed and analyzed by using the SPSS version 23 .

\section{Measurements}

Height: A measuring scale was used, fixing with the wall to measure the respondents' height. The individual respondent was asked to remove shoes or slippers and hat or clips from the head and stand facing forward with their feet put together, heels against the scale and knees forward looking straight forward and not looking up. Height was recorded to the nearest centimeter. 
Weight: For measuring the weight of the respondent, a digital bathroom scale was used. The individual respondent was asked to remove shoes or slippers and step onto the scale putting to foot together standing facing forward and arms on the body's side. The weight was recorded in kilograms with two decimal.

MUAC: For measuring the MUAC of the respondent, a MUAC tape was used. The individual respondent was asked to bend their left arm, and the mid-point of the arm from the olecranon to acromion process was identified. With the arm hanging straight down, MUAC was tape wrapped around the arm at the midpoint of the arm. MUAC was recorded to the nearest $1 \mathrm{~mm}$.

\section{Results}

A total of 357 participants in this study, among them 157 (44.0\%) were from Class IV, and the rest $200(56.0 \%)$ were from Class V. Boys and girls percentage was $49.9 \%$ and 50.1\%, respectively. Maximum 322 (90.2\%) children were aged between 10-12 years, and 21 (5.9\%) were below 10 years, and only 14 (3.9\%) were more than 12 years old. The mean age was $10.83 \pm 1.03$ years.

Table 1. Mean anthropometric measurement

\begin{tabular}{ll}
\hline Anthropometry & Mean \pm SD \\
\hline Weight $(\mathrm{kg})$ & $32.40 \pm 7.21$ \\
\hline Height $(\mathrm{cm})$ & $141.22 \pm 8.52$ \\
\hline MUAC $(\mathrm{cm})$ & $19.65 \pm 2.31$ \\
\hline
\end{tabular}

The participants' mean weight was $32.40 \pm 7.21 \mathrm{~kg}$, mean height $141.22 \pm 8.52 \mathrm{~cm}$, and the mean MUAC was $19.65 \pm 2.31 \mathrm{~cm}$.

Table 2. Height for Age Z score

\begin{tabular}{ll}
\hline HAZ & Frequency $(\mathrm{n})$ \\
\hline Normal & $326(91.3 \%)$ \\
\hline Stunted & $28(7.8 \%)$ \\
\hline Severe Stunted & $3(0.8 \%)$ \\
\hline
\end{tabular}

According to the Height for Age (HAZ) score, the maximum participants were $91.3 \%$ normal, and a few $8.6 \%$ were stunted and severely stunted according to the Height for Age (HAZ) score.

Table 3. Weight for Age Z score

\begin{tabular}{ll}
\hline WAZ & Frequency $(\mathrm{n})$ \\
\hline Normal & $318(89.1 \%)$ \\
\hline Underweight & $34(9.5 \%)$ \\
\hline Severe underweight & $5(1.4 \%)$ \\
\hline
\end{tabular}

According to the Weight for Age (WAZ) score, a maximum of $89.1 \%$ of participants was normal, and a few $10.9 \%$ were underweight and severe underweight according to the Weight for Age (WAZ) score. 
Table 4. Association between Weight for Age Z score and Family size

\begin{tabular}{lll}
\hline Factors & Normal & Underweight \\
\hline Family size & & \\
\hline 3-4 Person & $155(43.4 \%)$ & $11(3.1 \%)$ \\
\hline$>4$ Persons & $163(45.7 \%)$ & $28(7.8 \%)$ \\
\hline Anthelminthic drug use & \\
\hline Taken regularly & $269(75.4 \%)$ & $12(3.4 \%)$ \\
\hline Irregular & $27(7.6 \%)$ & $49(13.7 \%)$ \\
\hline
\end{tabular}

Table 4. shows that increasing the number of family members and the number of underweight children also increases. It also shows that the children who irregularly used anthelminthic drugs were underweight, which is statistically significant $(\mathrm{p}<0.05)$.

\section{Discussion}

This cross-sectional comparative study was conducted to determine the nutritional status of primary school children with the mid-day meal program. A total of 357 primary school children were selected for this study by systematic sampling from 05 Government Primary Schools of Sundarganj Upazila of Gaibandha District, Bangladesh. A semi-structured questionnaire was used to collect data from the respondents through face to face interviews. The participants were from Class IV, and V and most of them were aged between 10-12 years and boys-girls ratio was almost the same.

Most of the children (78.8\%) used to take anthelminthic drugs regularly, and only $3.4 \%$ were underweight. Some children $(21.3 \%)$ were irregular in taking anthelminthic drugs, and $13.7 \%$ were underweight.

It was revealed by this study that the mean weight of children was $32.40 \pm 7.21 \mathrm{~kg}$ irrespective of age and sex, the mean height of children was $141.22 \pm 8.52 \mathrm{~cm}$, and the mean mid-upper arm circumference (MUAC) was $19.65 \pm 2.31 \mathrm{~cm}$. In comparison with Abbottabad, Pakistan, they found 16.82 $\pm 2.68 \mathrm{~cm}$ MUAC among the 9-10 years old school children (Handa R, 2008).

This study found that $91.3 \%$ and $89.1 \%$ of children were normal in height for age (HAZ) and weight for age (WAZ) indices of nutritional status. This study result was closely similar to the result of Siddique S et al., 2013. They found $90.1 \%$ of normal children by HAZ.

This study found that $89.1 \%$ of children were normal in weight for age (WAZ) indices. Still, it was found only 33.9\% normal children in Bangalore (Byadagi S, 2015), 53.28\% normal children in Sirajgong (Hussein M, 2013), and only $16.0 \%$ were normal among the school-age slum children (Yeasmin S, 2016). This indicates that the prevalence of undernutrition was less at Sudarganj, Gaibandha.

The mid-day meal program was commenced in the selected 5 schools within April and May of 2016, and the meal was served every working day except Thursday and the examination days. The mid-day meal was Hotchpotch which was made up of rice (around 125 grams), pulses (10-15 grams), oil and seasonal vegetables (40-50 grams). This was not matched with the model menu of mid-day school meal made by the National Institute of Nutrition, Hyderabad. The model menu rice/cereals should be 75 gram, pulses 30 gram and vegetables 60 gram. Though the desired ingredients were less in quantity than the model menu, the nutritional status is quite acceptable among the primary school children with the mid-day meal program. 


\section{Conclusion}

The mid-day meal program in the school is popular in developing countries. It prevents hunger among school children during the school period. This study revealed that children with the mid-day meal program's overall nutritional status were satisfactory by height for age (HAZ) and weight for age (WAZ) indices of nutritional status. A longitudinal study is suggested to reveal further information regarding mid-meal program.

\section{References}

ADA. (2010). Position of the American Diabetic Association: Child and Adolescence nutrition assistance programs. USA: American Diabetic Association.

Byadagi S, S. S. (2015). Comparison of Nutritional Status of School Children with and without Mid-Day Meal Programme. Journal of Environment and Ecology, 69-75.

Chabra P, G. S. (1996). Health and nutritional status of boys aged 6 to 12 years in a children observation home. Indian Journal of Public Health, 126-9.

Handa R, A. F. (2008). Assessment of nutritional status of 7-10 years school going children of Allahabad district: A Review. Middle-East Journal of Scientific Research, 109-15.

Hasan I, Z. M. (2011). An assessment of nutritional status of the children of government urdu higher primary schools of Azad Nagar and its surrounding areas of Bangalore. Archives of Applied Science Research, 167-176.

Hussein M, N. K. (2013). Nutritional Status of Primary School Children from Low Income Households in Jordan. Journal of Natural Sciences Research, 61-67.

JC, W. (1994). Introduction, causes and mechanisms of linear growth retardation (stunting). European Journal of Clinical Nutrition, 1-4.

R, C. (2007). Nutrition education: Linking research, theory and practice. Massachusetts: Jones and Bartlett Publishers.

Story M, L. L. (2002). School-based nutrition education for young adolescents: Feasibility and process evaluation of the TEENS study. Journal of School Health, 121-7.

Yeasmin S, I. K. (2016). Prevalence and determinants of undernutrition among school-age slum children in Dhaka city, Bangladesh. Journal of Nutrition and Health Science, 1-8. 